\title{
Respiratory mechanics and morphometric changes during pneumoperitoneum in normal rats
}

\author{
L.F.P. Moreira, C.F. Gobbi, M. Feijóo, P.R.M. Rocco, W.A. Zin
}

Respiratory mechanics and morphometric changes during pneumoperitoneum in normal rats. L.F.P. Moreira, C.F. Gobbi, M. Feijóo, P.R.M. Rocco, W.A. Zin. CERS Journals Ltd 1997.

ABSTRACT: Pneumoperitoneum may give rise to several respiratory changes; nevertheless, no comprehensive analysis of respiratory mechanics has been performed under this condition.

Respiratory mechanics and thoracoabdominal morphometry were evaluated in six sedated, anaesthetized, paralysed, and mechanically-ventilated rats before (control) and during pneumoperitoneum. After airway occlusion at end-inspiration, respiratory system, pulmonary, and chest wall resistive pressures $(\Delta P 1, \mathrm{rs}, \Delta P 1, \mathrm{~L}$ and $\Delta P 1, \mathrm{cw}$, respectively) and viscoelastic/inhomogeneous pressures $\left(\Delta P_{2}, \mathrm{rs}, \Delta P_{2}, \mathrm{~L}\right.$ and $\Delta P 2$,cw, respectively) were determined. Total pressure changes $(\Delta P$ tot $)$ were calculated as the sum of $\Delta P_{1}$ and $\Delta P_{2}$, yielding the values of $\Delta P$ tot,rs, $\Delta P_{\text {tot, }, \mathrm{L} \text { and }}$ $\Delta \boldsymbol{P}_{\text {tot,cw, }}$ respectively. Respiratory system, lung, and chest wall static $\left(\boldsymbol{E}_{\mathrm{st}, \mathrm{rs},}, \boldsymbol{E}_{\mathrm{st}, \mathrm{L}}\right.$ and $E_{\mathrm{st}, \mathrm{cw}}$, respectively), and dynamic elastances $\left(E_{\mathrm{dyn}, \mathrm{rs}}, E_{\mathrm{dyn}, \mathrm{L}}\right.$ and $E_{\mathrm{dyn}, \mathrm{cw}}$, respectively), and the corresponding changes in elastance $(\Delta E)$ (calculated as $E_{\text {dyn- }} E_{\text {st }}$ ) were also obtained. Chest wall configuration both at functional residual capacity $(F R C)$ and end-inspiration (FRC + tidal volume $(V T))$ was also evaluated in another four rats.

Pneumoperitoneum significantly increased $\Delta \boldsymbol{P}_{\text {tot,rs, }} \Delta \boldsymbol{P}_{\text {tot,cw }}, \Delta \boldsymbol{P}_{2}, \mathrm{rs}, \mathbf{A} \boldsymbol{P}_{2, \mathrm{cw}}, \Delta \boldsymbol{E}_{\mathrm{rs}}$, $\Delta \boldsymbol{E}_{\mathrm{cw}}, \boldsymbol{E}_{\mathrm{st}, \mathrm{rs}}, \boldsymbol{E}_{\mathrm{st}, \mathrm{L}}$ and $\boldsymbol{E}_{\mathrm{st}, \mathrm{cw}}$. Lateral and anteroposterior diameters increased significantly, with the exception of lateral diameters at the level of crista iliaca. Cephalocaudal diameter and FRC decreased.

In conclusion, pneumoperitoneum augments elastances and increases the pressure dissipated against viscoelasticity/inhomogeneity of the respiratory system and chest wall. These changes are related to a cephalad displacement of the diaphragm plus changes in thoracoabdominal configuration.

Eur Respir J 1997; 10: 1321-1326.
Laboratory of Respiration Physiology, Carlos Chagas Filho Biophysics Institute, Federal University of Rio de Janeiro, Ilha do Fundão, Rio de Janeiro, Brazil.

Correspondence: W.A. Zin

Universidade Federal do Rio de Janeiro

Centro de Ciências da Saúde

Instituto de Biofísica Carlos Chagas Filho Ilha do Fundão

21949-900 Rio de Janeiro

Brazil

Keywords: Constant flow inflation elastance

mechanical inhomogeneities

morphometry

pneumoperitoneum

viscoelasticity

Received: August 221996

Accepted after revision January 201997

Supported by the Brazilian Council for Scientific and Technological Development (CNPq), Financing for Studies and Projects (FINEP), and Graduated Teaching and Research Council of the Federal University of Rio de Janeiro (CEPG-UFRJ).
The use of laparoscopic techniques in surgery is increasing in popularity. During laparoscopy, a pneumoperitoneum is generated, which may yield several respiratory changes, e.g. pulmonary atelectasis [1], decreased functional residual capacity (FRC) and vital capacity (VC) [1-3], reduced pulmonary compliance $[4,5]$, and increased peak airway pressure $[2,6]$. Although these alterations are important, no comprehensive analysis of respiratory mechanics has previously been reported during pneumoperitoneum. Thus, the present investigation was designed to evaluate the effects of pneumoperitoneum on respiratory system, pulmonary, and chest wall elastic, viscous, and viscoelastic mechanical properties, thoracoabdominal morphometry, and changes in FRC in anaesthetized paralysed rats.

\section{Materials and methods}

Ten male adult Wistar rats were initially sedated with diazepam (5 mg i.p.), anaesthetized with pentobarbital sodium (20 $\mathrm{mg} \cdot \mathrm{kg}$ i.p.), and a snugly-fitting cannula (1.5 mm internal diameter (ID)) was introduced into the trachea. They were then placed in the supine position on a surgical table. An Insyte I.V. 18-gauge catheter (Becton Dickinson Vascular Access, Sandy, UT, USA) was inserted into the peritoneal cavity in the mid-line, about 2.0 $\mathrm{cm}$ cephalad to the pubic bone. An indwelling catheter segment of about $1 \mathrm{~cm}$ was positioned, and the needle was then removed. The catheter was secured in place and the airtightness assured by stitching the skin around the catheter. Pneumoperitoneum was produced by injecting room air through the catheter until an intra-abdominal pressure of $12 \pm 1.2( \pm \mathrm{SD}) \mathrm{cmH}_{2} \mathrm{O}$ was reached.

In order to measure respiratory mechanics, six rats

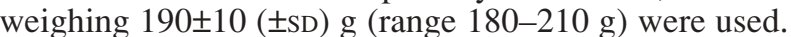
An adequate pneumotachograph, constructed according to Mortola and Noworaj [7], was connected to the tracheal cannula for the measurements of airflow $\left(V^{\prime}\right)$, and, by electronic integration, changes in tidal volume $(V \mathrm{~T})$. The flow resistance of the equipment $(R$ eq $)$, tracheal cannula included, was constant at flow rates of up to 26 $\mathrm{mL} \cdot \mathrm{s}^{-1}$ and amounted to $0.125 \mathrm{cmH}_{2} \mathrm{O} \cdot \mathrm{mL}^{-1} \cdot \mathrm{s}$. Equipment resistive pressure $\left(R \mathrm{eq} \cdot V^{\prime}\right)$ was subtracted from respiratory system and pulmonary viscous pressure, so that 
the present results represent intrinsic values. Because abrupt changes of diameter were not present in the circuit, errors in measurement of flow resistance were probably avoided $[8,9]$. The equipment dead space was 0.4 $\mathrm{mL}$.

Tracheal pressure $\left(P_{\text {tr }}\right)$ was measured with a HewlettPackard 270 differential pressure transducer (Waltham, MA, USA). Changes in oesophageal pressure ( $\left.P_{\text {oes }}\right)$, which reflects chest wall pressure $(P \mathrm{cw})$, were measured with a $30 \mathrm{~cm}$ long water-filled catheter (PE-240) with side holes at the tip connected to a PR23-2D-300 Statham differential pressure transducer (Hato Rey, Puerto Rico). The catheter was passed into the stomach and then slowly returned into the oesophagus; its proper positioning was assessed using the "occlusion test" [10]. The frequency responses of the pressure measurement systems $\left(P_{\text {tr }}\right.$ and $\left.P_{\text {oes }}\right)$ were flat up to $20 \mathrm{~Hz}$, without appreciable phase shift between the signals. All signals were conditioned and amplified in a Beckman type R Dynograph (Schiller Park, IL, USA) and recorded on paper at a speed of $5 \mathrm{~mm} \cdot \mathrm{s}^{-1}$. Flow and pressure signals were also passed through 8-pole Bessel filters (902LPF; Frequency Devices, Haverhill, MA, USA) with the comer frequency set at $100 \mathrm{~Hz}$, sampled at $200 \mathrm{~Hz}$ with a 12-bit analogue-to-digital converter (DT2801A; Data Translation, Marlboro, MA, USA), and stored on a computer (PCAT; IBM, Armonk, NY, USA). All data were collected using LABDAT software (RHT-InfoData Inc., Montreal, Quebec, Canada).

Muscle relaxation was achieved with gallamine triethyliodide $\left(2 \mathrm{mg} \cdot \mathrm{kg}^{-1}\right.$ i.p. $)$, and artificial ventilation was provided by a Salziner constant flow ventilator (Instituto do Coração-USP, São Paulo, Brazil). During the test breaths, a $5 \mathrm{~s}$ end-inspiratory pause could be generated by adjusting the ventilator settings, whereas during the baseline ventilation no pause was used. In order to avoid the effects of different flows and volumes $[11,12]$ and inspiratory duration [13] on the variables measured, special care was taken to keep $V \mathrm{~T}(=2 \mathrm{~mL})$ and $V^{\prime}(=10$ $\mathrm{mL} \cdot \mathrm{s}^{-1}$ ) constant in all animals.

The measurements were performed before and immediately after the injection of room air into the peritoneal space. The experiments did not last more than $40 \mathrm{~min}$. Respiratory mechanics were measured from end-inspiratory occlusions after constant flow inflations [14]. Although this method has been used for a long time, the significance of the variables measured has only recently been clarified [13, 15-18]. After end-inspiratory occlusion, there is an initial fast drop in tracheal pressure $(\Delta P 1, \mathrm{rs})$ from the preocclusion value down to an inflection point $(P \mathrm{i}, \mathrm{rs})$, followed by a slow pressure decay $(\Delta P 2, \mathrm{rs})$, until a plateau is reached. This plateau corresponds to the elastic recoil pressure of the respiratory system. $\Delta P 1$,rs selectively reflects the combination of airways, pulmonary, and chest wall Newtonian resistances in normal animals [11, 13, 16-18] and humans [12]. $\Delta P 2$,rs reflects stress relaxation, or viscoelastic properties, of the lung and chest wall tissues, together with a small contribution of pendelluft in normal situations $[12,17,18]$.

The same procedures apply to the chest wall pressure $\left(P_{\mathrm{cw}}\right)$ yielding the values of $\Delta P 1, \mathrm{cw}, P \mathrm{i}, \mathrm{cw}, \Delta P 2, \mathrm{cw}$ and $P$ el,cw, respectively. Transpulmonary pressures $(\triangle P 1, \mathrm{~L}$, $P \mathrm{i}, \mathrm{L}, \Delta P 2, \mathrm{~L}$ and $P \mathrm{el}, \mathrm{L})$ were calculated by subtracting the chest wall pressure from the corresponding values pertaining to the respiratory system. Total pressure drop ( $\Delta P_{\text {tot }}$ ) is equal to the sum of $\Delta P 1$ and $\Delta P 2$, yielding the values of $\Delta P$ tot,rs, $\Delta P$ tot, $\mathrm{L}$, and $\Delta P$ tot,cw.

Respiratory system, lung and chest wall static elastances ( $E_{\text {st,rs, }} E_{\text {st,L }}$ and $E_{\text {st,cw, }}$ respectively) were calculated by dividing $P \mathrm{el}, \mathrm{rs}, P \mathrm{el}, \mathrm{L}$, and $P \mathrm{el}, \mathrm{cw}$, respectively, by $V \mathrm{~T}$. Dynamic elastances of the respiratory system, lung, and chest wall ( $E$ dyn,rs, $E$ dyn,L and $E$ dyn,cw, respectively) were obtained by dividing $P \mathrm{i}, \mathrm{rs}, P \mathrm{i}, \mathrm{L}$ and $P \mathrm{i}$,cw, respectively, by $V \mathrm{~T} . \Delta \mathrm{E}$ was calculated as the difference $E$ dyn - Est, yielding the values of $\Delta E_{\mathrm{rs}}, \Delta E \mathrm{~L}$, and $\Delta E_{\mathrm{cw}}$. The data concerning respiratory system, lung, and chest wall elastances were presented in terms of static elastance and $\Delta E$ instead of dynamic elastances, since they represent, respectively, the elastic and viscoelastic properties of the respiratory system [19]. Measurements of respiratory mechanics were performed 8-10 times in each animal in all instances. Immediately before each data collection period, the airways were aspirated to remove possible collection of mucus, and the respiratory system was inflated three times to total lung capacity (TLC) to maintain constant volume history.

The delay between the beginning and the end of the valve closure $(10 \mathrm{~ms})$ was allowed for by back extrapolation of the pressure records to the actual time of occlusion, and the corrections in pressure, although very small, were performed as described previously [11].

All data were analysed using ANADAT data analysis software (RHT-InfoData Inc., Montreal, Quebec, Canada).

Chest wall configuration and FRC changes were determined in four male Wistar rats $(195 \pm 10( \pm \mathrm{SD}) \mathrm{g}$, range 185-210 g) prepared as described previously [20], and ventilated in the same manner as the other six rats in the study. Thoracoabdominal circumferences (C), anteroposterior (Dap), and lateral (D1) diameters at the third intercostal space (ic), xiphoid (x), and crista iliaca (ci) levels were measured at control and during pneumoperitoneum, both at FRC and FRC $+V \mathrm{~T}$. Circumferences were measured with an inextensible thread, and diameters were obtained directly with calipers. The measurements were performed three times in each animal by the same investigator, under the same circumstances as described for the mechanical analysis. Special care was taken to perform the measurements at the same reference points and to avoid errors due to the soft tissue compressibility [20].

Pulmonary cephalocaudal diameter (Dcc), distance from the lung apex to the diaphragmatic dome, was also determined in these four Wistar rats [21] before (control) and during pneumoperitoneum at FRC. For this purpose, two needle shafts were introduced transversally through the rat skin at $90^{\circ}$ relative to its body length, at the 3rd intercostal space and xiphoid levels. Under radioscopic examination, two lengths were measured on the monitor: 1) between the two needle shafts; and 2) the lung apex-diaphragmatic dome distance. Since the space between the two needles was measured in the rats with calipers and the display was linear, Dcc could be easily calculated. The measurements were performed three times in each animal by the same investigator, under the same circumstances as described for the mechanical analysis. 
In addition, the possible changes in functional residual capacity $(\triangle \mathrm{FRC})$ induced by the experimental protocol were also measured in all animals [20]. For this purpose, the same method as used in gas chromatography for flow and volume quantification was applied. A $1 \mathrm{~mL}$ graduated pipette with a soap meniscus in its lumen lay horizontally, and its tip was connected via a three-way stopcock to the breathing circuit. Just before abdominal inflation, the ventilator was disconnected and at FRC the stopcock was positioned to communicate the airways to the pipette. The abdomen was then rapidly inflated and the displacement of the soap meniscus, i.e. lung volume change, was determined. The manoeuvre did not last more than $20 \mathrm{~s}$. The experiments lasted less than $40 \mathrm{~min}$.

Statistical analysis was performed by means of Student's paired t-test, and the significance level was established at $5 \%$. Values are presented as mean \pm SEM unless otherwise specified. A p-value less than 0.05 was considered statistically significant.

\section{Results}

Table 1 presents the mean values ( \pm SEM) of inspiratory flow, $V \mathrm{~T}$, respiratory system, lung, and chest wall pressure changes, static elastances, and change in elastance obtained before (Control) and during pneumoperitoneum.

Pneumoperitoneum modified the respiratory mechanical profile. It can be seen in figure 1 a that $E_{\text {st,rs, }} E_{\text {st,L }}$ and $E$ st,cw increased significantly during pneumoperitoneum $(89,54$, and $217 \%$, respectively). In addition, $\Delta E_{\mathrm{rs}}$ and $\Delta E_{\mathrm{cw}}$ increased by 53 and $446 \%$, respectively, whereas $\Delta E_{\mathrm{L}}$ remained unaltered (fig. 1b). Pneumoperitoneum also led to statistically significant increases in $\Delta P$ tot,rs $(27 \%)$, secondary to a rise in $\Delta P 2$,rs $(49 \%)$. These were consequent to changes in chest wall parameters, since only $\Delta P$ tot,cw $(188 \%)$ and $\Delta P 2$,cw $(428 \%)$ increased significantly. These results are depicted in figure 2 .

Table 1. - Respiratory data before (Control) and during pneumoperitoneum (PNE)

\begin{tabular}{|c|c|c|}
\hline & Control & PNE \\
\hline$V^{\prime} \mathrm{mL} \cdot \mathrm{s}^{-1}$ & $10.05 \pm 0.09$ & $10.01 \pm 0.19$ \\
\hline$V \mathrm{~T} \mathrm{~mL}$ & $2.00 \pm 0.02$ & $1.95 \pm 0.04$ \\
\hline$\Delta P$ tot,rs $\quad \mathrm{cmH}_{2} \mathrm{O}$ & $4.12 \pm 0.24$ & $5.25 \pm 0.29 *$ \\
\hline$\Delta P 1, \mathrm{rs} \quad \mathrm{cmH}_{2} \mathrm{O}$ & $2.18 \pm 0.12$ & $2.36 \pm 0.12$ \\
\hline$\Delta P_{2, \mathrm{rs}} \mathrm{cmH}_{2} \mathrm{O}$ & $1.94 \pm 0.17$ & $2.89 \pm 0.24 *$ \\
\hline$\Delta P$ tot, $\mathrm{L} \quad \mathrm{cmH}_{2} \mathrm{O}$ & $3.56 \pm 0.28$ & $3.63 \pm 0.36$ \\
\hline$\Delta P 1, \mathrm{~L} \mathrm{cmH} \mathrm{O}_{2} \mathrm{O}$ & $1.84 \pm 0.16$ & $1.94 \pm 0.12$ \\
\hline$\Delta P_{2, \mathrm{~L}} \quad \mathrm{cmH}_{2} \mathrm{O}$ & $1.72 \pm 0.17$ & $1.69 \pm 0.31$ \\
\hline$\Delta P$ tot,cw $\quad \mathrm{cmH}_{2} \mathrm{O}$ & $0.56 \pm 0.08$ & $1.62 \pm 0.23 *$ \\
\hline$\Delta P 1, \mathrm{cw} \quad \mathrm{cmH}_{2} \mathrm{O}$ & $0.34 \pm 0.05$ & $0.42 \pm 0.05$ \\
\hline$\Delta P 2, \mathrm{cw} \quad \mathrm{cmH}_{2}^{2} \mathrm{O}$ & $0.23 \pm 0.02$ & $1.20 \pm 0.21 *$ \\
\hline$E_{\text {st }, \mathrm{rs}} \quad \mathrm{cmH}_{2} \mathrm{O} \cdot \mathrm{mL}^{-1}$ & $3.46 \pm 0.11$ & $6.54 \pm 0.48 *$ \\
\hline$E_{\mathrm{st}, \mathrm{L}} \quad \mathrm{cmH}_{2}^{2} \mathrm{O} \cdot \mathrm{mL}^{-1}$ & $2.71 \pm 0.18$ & $4.17 \pm 0.58 *$ \\
\hline$E_{\text {st }, \mathrm{cw}} \mathrm{cmH}_{2} \mathrm{O} \cdot \mathrm{mL}^{-1}$ & $0.75 \pm 0.10$ & $2.38 \pm 0.53 *$ \\
\hline$\Delta$ Ers $\mathrm{cmH}_{2} \mathrm{O} \cdot \mathrm{mL}^{-1}$ & $0.97 \pm 0.08$ & $1.49 \pm 0.14 *$ \\
\hline$\Delta \mathrm{El} \mathrm{cmH}_{2} \mathrm{O} \cdot \mathrm{mL}^{-1}$ & $0.86 \pm 0.09$ & $0.87 \pm 0.16$ \\
\hline$\Delta \mathrm{Ecw} \quad \mathrm{cmH}_{2} \mathrm{O} \cdot \mathrm{mL}^{-1}$ & $0.11 \pm 0.01$ & $0.62 \pm 0.12$ \\
\hline
\end{tabular}

Values are presented as mean \pm SEM of six animals (8-10 determinations $\left.\cdot r^{-1}{ }^{-1}\right) . V^{\prime}$ : flow; $V$ T: tidal volume; rs: respiratory system; L: lung; cw: chest wall; $\Delta P$ tot, $\Delta P 1$ and $\Delta P 2$ : total, initial and slow pressure drops after end-inspiratory occlusion, respectively; $E$ st: static elastance; $\Delta \mathrm{E}$ : difference between dynamic and static elastance. *: $\mathrm{p}<0.05$, compared to respective control value.
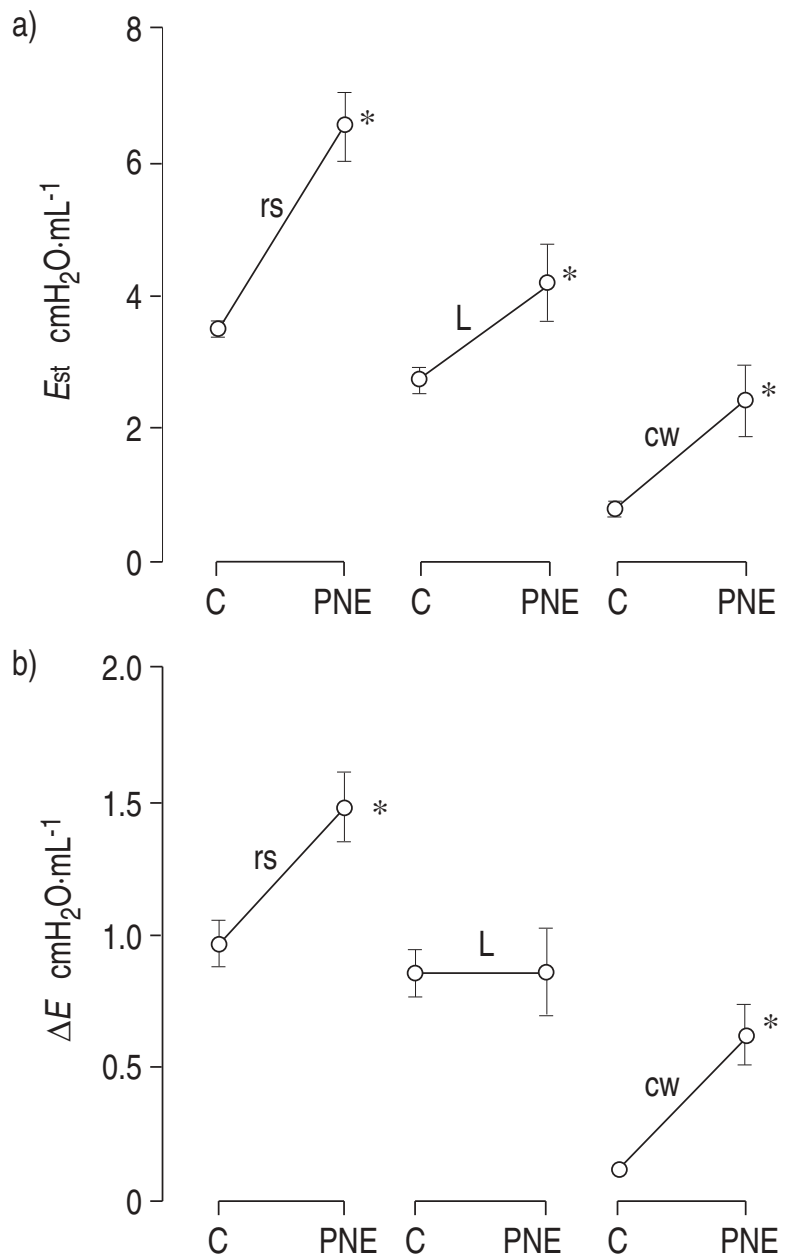

Fig. 1 - a) Respiratory system (rs), lung (L), and chest wall (cw) static elastance $\left(E_{\mathrm{st}}\right)$; and b) differences between dynamic and static elastance $(\Delta \mathrm{E})$ before (Control $(\mathrm{C}))$ and during pneumoperitoneum (PNE). Values are presented as mean \pm SEM of 6 rats $(8-10$ determinations $\cdot$ rat $\left.^{-1}\right)$. When not depicted, error bars are smaller than symbols. *: $\mathrm{p}<0.01$, compared to control value.

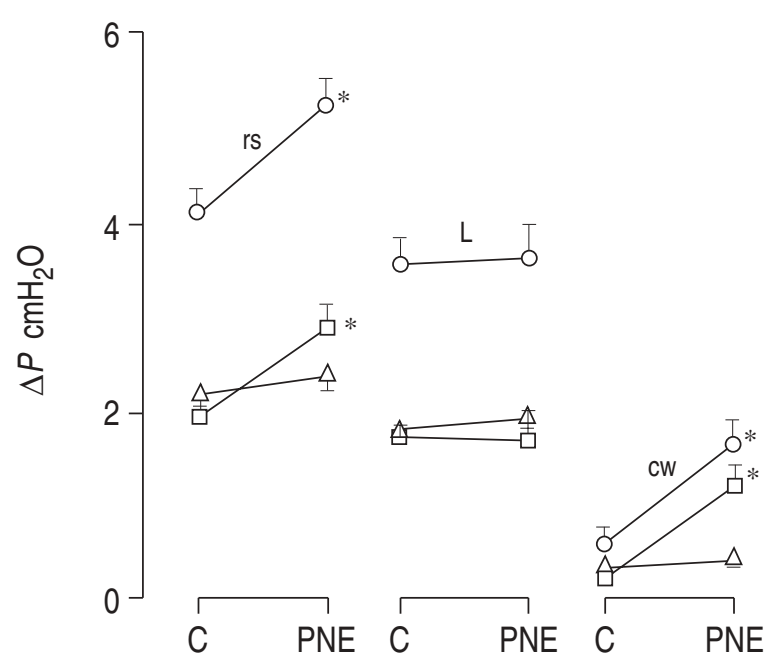

Fig. 2. - Respiratory system (rs), lung (L), and chest wall (cw) total pressure drop $\left(\Delta P_{\text {tot }}\right)$ its viscous $(\Delta P 1)$, and viscoelastic/inhomogenous $\left(\Delta P_{2}\right)$ components after end-inspiratory airway occlusion in rats, before (Control (C)) and during pneumoperitoneum (PNE). Values are presented as mean \pm SEM of 6 rats $\left(8-10\right.$ determinations $\cdot$ rat $\left.^{-1}\right)$. *: $\mathrm{p}<0.05$, compared to control value. ○—०: $\Delta P_{\text {tot }} \Delta-\Delta: \Delta P 1 ; \square-\square: \Delta P 2$. 


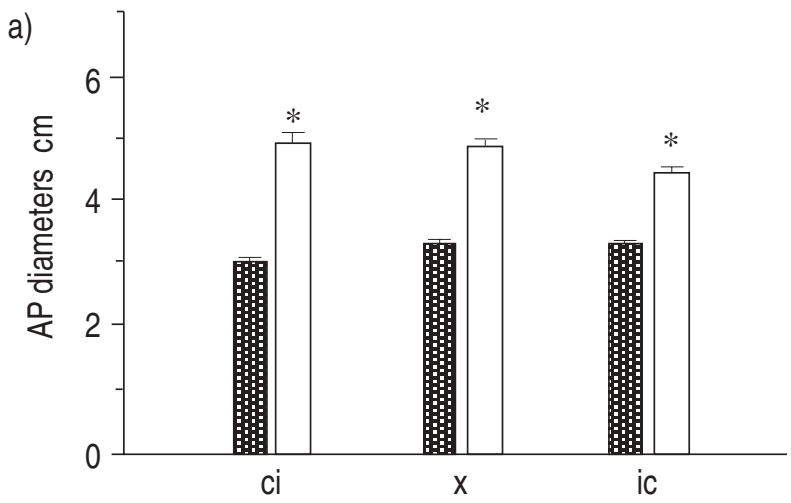

b)
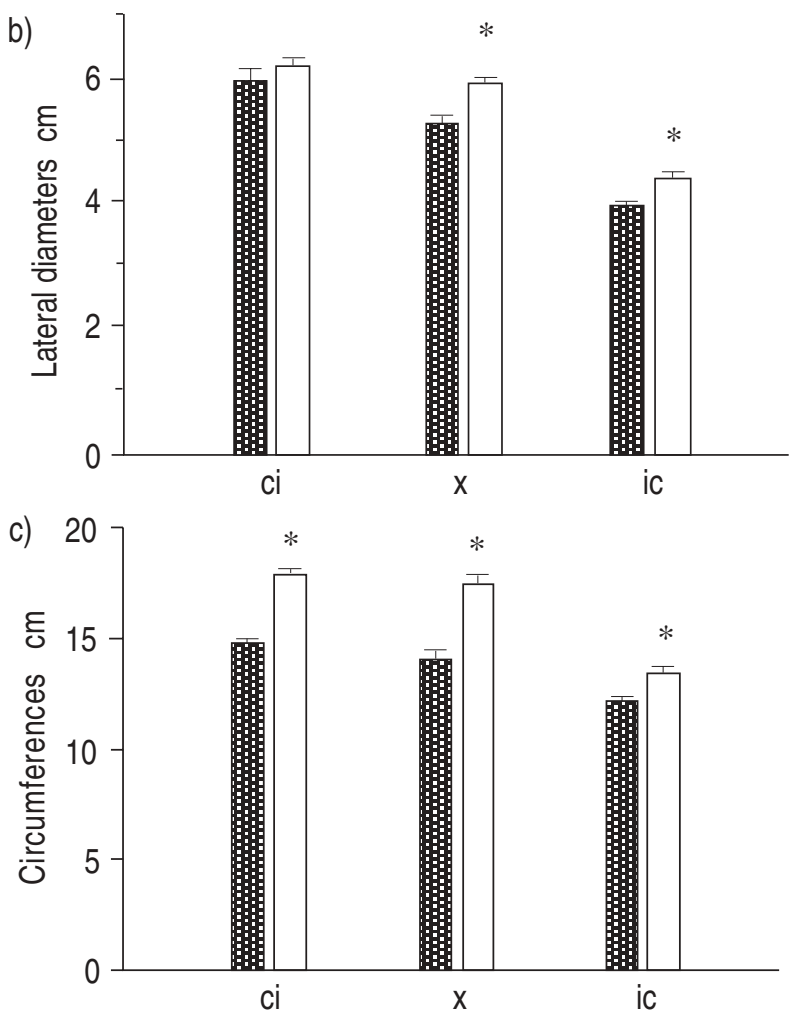

Fig. 3. - Thoracoabdominal dimensions measured at functional residual capacity (FRC) before (Control (C)) and during pneumoperitoneum (PNE), a) Anteroposterior (AP) diameters; b) lateral (LAT) diameters; and c) circumferences at crista iliaca (ci), xiphoid (x), and 3 rd intercostal space (ic) levels. Values are presented as mean \pm SEM of 6 rats $\left(8-10\right.$ determinations $\cdot$ rat $\left.^{-1}\right)$. * $: \mathrm{p}<0.05$ compared to control value. 日月:日8: : Control; $\square$ : PNE.

Figure 3 shows the data on thoracoabdominal configuration measured before and during pneumoperitoneum at FRC. All diameters and circumferences, except the lateral diameter at the level of the crista iliaca, increased significantly. Pulmonary cephalocaudal diameter decreased significantly after injection of air into the peritoneal space, from $2.77 \pm 0.08$ to $2.54 \pm 0.06 \mathrm{~cm}(9 \%)$. FRC was also reduced during pneumoperitoneum $(\triangle \mathrm{FRC} 0.33 \pm$ $0.06 \mathrm{~mL}$ ).

\section{Discussion}

Pneumoperitoneum reduces pulmonary volumes [1-3], and may affect respiratory mechanics $[4,5]$, as observed previously. However, no data have previously been reported concerning respiratory system, lung, and chest wall viscous, elastic, and viscoelastic mechanical properties during pneumoperitoneum.

Laparoscopy requires the generation of a pneumoperitoneum, most commonly achieved with the insufflation of $\mathrm{CO}_{2}$ into the peritoneal cavity. Pulmonary atelectasis, decreased FRC, high peak inspiratory pressures, and raised arterial $\mathrm{CO}_{2}\left(\Delta \mathrm{CO}_{2}<10 \mathrm{mmHg}\right)$ and alveolar $\mathrm{CO}_{2}$ $\left(\Delta \mathrm{CO}_{2}<8 \mathrm{mmHg}\right)$ may result, as a consequence of the greater intra-abdominal pressure, and absorption of $\mathrm{CO}_{2}$ [2].

In the present investigation, peritoneal insufflation yielded an increase of $12.2 \pm 1.2 \mathrm{cmH}_{2} \mathrm{O}$ in abdominal pressure, which is similar to the values reported during laparoscopic cholecystectomy [22] or tubal ligation [3] $\left(12-18 \mathrm{cmH}_{2} \mathrm{O}\right)$. However, pressure values up to 40 $\mathrm{cmH}_{2} \mathrm{O}$ can be used in gyneacological surgery [22].

In the present study, in order to avoid the effects of $\mathrm{CO}_{2}$, room air was injected intra-abdominally. The procedure is supported by the finding that when nitrous oxide was substituted for $\mathrm{CO}_{2}$ no increase in the levels of the latter could be detected in dogs [23]. Thus, only the mechanical changes subsequent to increased intraabdominal pressure are dealt with here.

Pneumoperitoneum yielded higher $E_{\text {st,L }}$ and $E_{\text {st,cw, }}$ which led to increased $E_{\text {st,rs }}$ (fig. 1), thus indicating that the elastic component of the respiratory impedance was augmented under the present experimental conditions. These results are in accordance with those achieved during abdominal effusions [21] and pneumoperitoneum $[2,4,5]$. The increase in $E$ st, $\mathrm{L}$ could be attributed to atelectasis at the lung base secondary to the cephalad movement of the diaphragmatic dome (see below), as also found previously [4, 20]. A higher $E$ st,L could also be due to the smaller FRC found during pneumoperitoneum, which moved the pulmonary resting volume to lower values along the pressure-volume $(P-V)$ curve of the lung, i.e. towards a less compliant region, and yielded airway closure. The significantly higher $E$ st,cw (fig. 1) could be ascribed to conformational changes of the chest wall (fig. 3), and also to the increased stiffness of the diaphragm as a result of its cephalad displacement.

$\Delta E_{\mathrm{rs}}$ and $\Delta E_{\mathrm{cw}}$ increased significantly during pneumoperitoneum, whereas $\Delta E \mathrm{~L}$ remained unaltered (fig. 1 ), suggesting that chest wall (and, thus, respiratory system) viscoelasticity/inhomogeneity became more prominent after pneumoperitoneum. This finding is confirmed by the increase in $\Delta P 2$,cw (fig. 2), as discussed below.

When airflow and tidal volume remain constant, changes in $\Delta P$ tot,rs reflect modification of respiratory system resistance, viscoelasticity and/or inhomogeneity. Pneumoperitoneum raised $\Delta P$ tot,rs. There was no signifi-

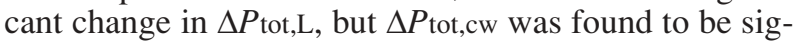
nificantly higher during pneumoperitoneum (table 1 and fig. 2).

It has been demonstrated in cats [11], dogs [13, 16, 17], and rats [24] that changes in $\triangle P 1, \mathrm{~L}$, when airflow and $V \mathrm{~T}$ remain constant, reflect pressure losses against Newtonian pulmonary resistances, whereas $\Delta P 1$,cw also contributes to the chest wall component of $\Delta P 1$,rs $[13$, 18]. Pneumoperitoneum did not induce significant changes in lung and chest wall Newtonian flow resistances. 
Variations in $\Delta P 2$,rs can be closely related to stress relaxation (or stress recovery) properties of lung and chest wall tissues (modelled by Kelvin bodies, each composed of an elastic element in parallel with a series elastance-resistance), together with a tiny contribution of pendelluft and asynchrony of movement within and between the chest wall components $[12,17,24]$. In other words, $\Delta P 2$ can reflect pressure losses due to viscoelastic properties and/or mechanical inhomogeneities of lung and chest wall. During pneumoperitoneum, $\Delta P 2$,cw increased significantly, augmenting $\Delta P 2$,rs. In a recent study Augusto et al. [21] showed that after intraperitoneal injection of $50 \mathrm{~mL}$ of saline solution $(0.9 \% \mathrm{NaCl})$ there were no statistically significant alterations in respiratory $\Delta P$ s. However, in the present study, chest wall viscoelastic/inhomogeneity pressure losses were substantial. This apparent discrepancy could be explained by the different conformational changes of the chest wall between the two studies (see below). Interestingly, $\Delta P 1, \mathrm{~L}$ and $\Delta P 2, \mathrm{~L}$ did not change in other models of disease (pleural effusion, pneumothorax and intraperitoneal effusion) leading to a decrease in FRC [21, 25], under experimen-tal conditions similar to the present one.

Although the methods used to measure configuration parameters could lead to error in the measurements, great care was taken to minimize this. Thus, the highest intraanimal value of $\mathrm{sD} /$ mean $(\mathrm{n}=3)$ in the determination of Dap, D1 and circumferences amounted to only $4.8 \%$. When Dcc was measured the greatest ratio was $6.3 \%$.

The conformational changes were similar at FRC and $\mathrm{FRC}+V \mathrm{~T}$, therefore only changes in FRC are shown (fig. 3 ). Circumferences and Dap values increased in the three levels studied. The variations in D1 were significant only at the xiphoid and intercostal levels. The most evident increase in D1 was found at the xiphoiod level, confirming the effect of the larger abdominal volume on the inferior rib cage. The same applies to the measurement of circumferences. Dap increased mostly at the level of the crista iliaca (fig. 3), where the distensibility of the abdominal wall is possibly larger due to the absence of bones in the anterior abdominal wall.

Dcc decreased during pneumoperitoneum because the diaphragm was pushed upwards. According to SHA et al. [1], using chest radiographs, during pneumoperitoneum there is a marked cephalad shift of the inspiratory and the expiratory position of the diaphragm. FRC was also reduced. Taking into account body weight $(\mathrm{BW}), \triangle \mathrm{FRC} /$ $\mathrm{BW}$ (after pneumoperitoneum) equals $2.3 \mathrm{~mL} \cdot \mathrm{kg}^{-1}$. Furthermore, according to CROSFILL and WidDicombe [26], in nonparalysed rats $\mathrm{FRC} / \mathrm{BW}$ equals $6 \mathrm{~mL} \cdot \mathrm{kg}^{-1}$. Thus, under the present experimental conditions, and assuming that FRC did not change with muscle paralysis, the total exhaled amount of gas was approximately $38 \%$ of FRC.

Interestingly, the injection of $50 \mathrm{~mL}$ of saline solution $(0.9 \% \mathrm{NaCl})$ into the abdominal cavity yielded a $\Delta$ FRC/BW value of $2.4 \mathrm{~mL} \cdot \mathrm{kg}^{-1}$ [21], a value similar to that found in the present study. However, Dap and C during pneumoperitoneum (expressed as percentage of control values) were greater than in the face of peritoneal effusion [21], namely: Dap,ci 62 vs 26\%, respectively; Dap,x 47 vs 11\%; Dap,ic 36 vs 3\%; Cci 21 vs 14\%; Cx 26 vs 8\%; and $\mathrm{Cic} 12$ vs $1 \%$. On the other hand, D1,ci (13 vs 4\%), and D1,x (17 vs 13\%) were greater during peritoneal effusion, but $\mathrm{D}$, ic was larger during pneumoperitoneum (10 vs 6\%). Finally, Dcc change was greater during peritoneal effusion (16 vs 9\%). Thus, it seems that the conformational changes induced by peritoneal effusion and pneumoperitoneum are different: because of the higher density of the saline solution, during abdominal effusion the fluid tends to accumulate at the dependent parts of the cavity, thus allowing greater D1 and Dcc than during pneumoperitoneum. The different conformational changes could also be responsible for the apparent discrepancy between the values of $\Delta P 2$ and $\Delta P$ tot found in the two studies. Finally, the conformational changes of the chest wall (diaphragm included) in the face of pneumoperitoneum could account for the increased $\Delta P 2$,w reported in the present study.

In conclusion, it seems that not only are elastic changes present during pneumoperitoneum but there is also a substantial loss of pressure dissipated against viscoelastic/ inhomogeneous segments of the chest wall. The mechanical findings were supported by measurements of chest wall morphometry, functional residual capacity and diaphragmatic displacement. Thus, during laparoscopic surgery the ventilator settings should be readjusted after the introduction of gas into the abdominal cavity because of the higher respiratory impedance found under these circumstances.

Acknowledgement: The authors thank A. Carlos de Souza Quaresma for skilful technical assistance.

\section{References}

1. Sha M, Ohmura A, Yamada M. Diaphragm function and pulmonary complications after laparoscopic cholecystectomy. Anesthesiology 1991; 75: A254.

2. Alexander GD, Noe FE, Brown EM. Anaesthesia for pelvic laparoscopy. Anesth Anal 1969; 48: 14-18.

3. Brown DR, Fishburne JI, Roberson VO, Hulka JF. Ventilatory and blood gas changes during laparoscopy with local anesthesia. Am J Obstet Gynecol 1976; 124 : 741-745.

4. Puri GD, Singh H. Ventilatory effects of laparoscopy under general anesthesia. Br J Anaesth 1992; 68: 211-213.

5. Johannsen G, Nidersen M, Juhl B. The effect of general anesthesia on the haemodynamic events during laparoscopy with $\mathrm{CO}_{2}$ insufflation. Acta Anaesthesiol Scand 1989; 33: 132-136.

6. Smith I, Benzie RJ, Gordon NLM, Kelman GR, Swapp GH. Cardiovascular effects of pneumoperitonial insufflation of carbon dioxide for laparoscopy. $\mathrm{Br} \mathrm{Med} J$ 1971; 3: 410-411.

7. Mortola JP, Noworaj A. Two-sidearm tracheal cannula for respiratory airflow measurements in small animals. J Appl Physiol: Respirat Environ Exercise Physiol 1983; 55: 250-253.

8. Chang HK, Mortola JP. Fluid dynamic factors in tracheal pressure measurements. J Appl Physiol: Respirat Environ Exercise Physiol 1981; 51: 218-225.

9. Loring SH, Elliot EA, Drazen JM. Kinetic energy loss and convective acceleration in respiratory resistance measurements. Lung 1979; 156: 33-42.

10. Baydur A, Behrakis PK, Zin WA, Jaeger M, Milic-Emili J. A simple method for assessing the validity of the 
oesophageal balloon technique. Am Rev Respir Dis 1982; 126: 788-791.

11. Kochi T, Okubo S, Zin WA, Milic-Emili J. Chest wall and respiratory system mechanics in cats: effects of flow and volume. J Appl Physiol 1988; 64: 2636-2646.

12. D'Angelo E, Calderini E, Torri G, Robbato FM, Bono D, Milic-Emili J. Respiratory mechanics in anesthetized paralyzed humans: effects of flow, volume, and time. $J$ Appl Physiol 1989; 670: 2556-2564.

13. Similowski T, Levy P, Corbeil C, et al. Viscoelastic behavior of lung and chest wall in dogs determined by flow interruption. $J$ Appl Physiol 1989; 67: 2219-2229.

14. Bates JHT, Rossi A, Milic-Emili J. Analysis of the behavior of the respiratory system with constant inspiratory flow. J Appl Physiol 1985; 58: 1840-1848.

15. Bates JHT, Baconnier P, Milic-Emili J. A theoretical analysis of the interrupter technique for measuring respiratory mechanics. J Appl Physiol 1988; 64: 2204-2214.

16. Bates JHT, Brown KA, Kochi T. Respiratory mechanics in the normal dog determined by expiratory flow interruption. J Appl Physiol 1989; 67: 2276-2285.

17. Bates JHT, Ludwig MS, Sly PD, Brown KA, Martin JG, Fredberg JJ. Interrupter resistance elucidated by alveolar pressure measurements in open-chest normal dogs. J Appl Physiol 1988; 65: 408-414.

18. Kochi T, Okubo S, Zin WA, Milic-Emili J. Flow and volume dependence of pulmonary mechanics in anesthetized cats. J Appl Physiol 1988; 64: 441-450.
19. Eissa NT, Ranieri VM, Corbeil C, Chassé M, Braidy J, Milic-Emili J. Effect of PEEP on the mechanics of the respiratory system in ARDS patients. J Appl Physiol 1992; 73: 1728-1735.

20. Zin WA, Martins MA, Silva PRM, Sakae RS, Carvalho ALI, Saldiva PHN. Effects of abdominal opening on respiratory system mechanics in ventilated rats. $J$ Appl Physiol 1989; 66: 2496-2501.

21. Augusto VM, Sousa AS, Moll RJ, Duarte JGC, Zin WA. Respiratory mechanics and morphometry after progressive intraperitonial effusion. Respir Physiol 1995; 102: 217-224.

22. Hanley ES. Anesthesia for laparoscopic surgery. Surg Clin North Am 1992; 72: 1013-1019.

23. Ivankovich AD, Miletich DJ, Albrecht RF, Heyman HJ, Bonnet RF. Cardiovascular effects of intraperitoneal insufflation with carbon dioxide and nitrous oxide in the dog. Anesthesiology 1975; 42: 281-287.

24. Saldiva PHN, Zin WA, Santos RLB, Eidelman DH, Milic-Emili J. Alveolar pressure measurement in openchest rats. J Appl Physiol 1992; 72: 302-306.

25. Sousa AS, Moll RJ, Pontes CF, Saldiva PHN, Zin WA. Mechanical and morphometrical changes in progressive bilateral pneumothorax and pleural effusion in normal rats. Eur Respir J 1995; 8: 99-104.

26. Crosfill ML, Widdicombe JG. Physical characteristics of the chest and lungs and the work of breathing in different mammalian species. J Physiol Lond 1961; 158: 1-14. 